\title{
Tailings initial consolidation and evaporative drying after deposition
}

\author{
A.L. Li URS Pty Ltd, Australia \\ K. Been Golder Associates Ltd., Canada \\ I. Wislesky Golder Associates Ltd., Canada \\ T. Eldridge Golder Associates S.A., Chile \\ D. Williams Golder Associates Pty Ltd, Australia
}

\section{Abstract}

Tailings and mine waste management has an ever-growing importance in mining, including the oil sands industry. Dewatering technologies are being adopted and further developed to reduce the environmental and social impacts of tailings management facilities as well as the risks associated with possible failure of dams that retain liquid or liquefiable tailings. The geotechnical performance of tailings deposits is one of the key issues that needs to be fully addressed for large mining projects, including oil sands projects. It has been demonstrated (Li et al., 2009) that the initial void ratio of tailings immediately following deposition is a critical parameter that affects the performance of tailings deposits under both static and seismic loading conditions, particularly the post-liquefaction stability of tailings deposits.

This paper presents a design method that draws upon geotechnical modelling techniques to predict the initial void ratio of tailings following self-weight consolidation and evaporative drying achieved through thin layer deposition. The self-weight consolidation model is based on a large strain consolidation theory (Gibson et al., 1967). For evaporative drying, the governing equation is based on a desiccation model (Gilliland and Sherwood, 1933) established for moisture migration within fine-grained soils due to evaporative drying, but the method also incorporates the soil-water characteristic curve equation (Fredlund and Xing, 1994). Analytical solutions have been derived for the governing equations. The modelling tools developed and presented in this paper provide a means to estimate an optimum layer thickness and drying period to increase in situ density of tailings and reduce the liquefaction potential of tailings deposits.

\section{Introduction}

Tailings dewatering technologies have been developed through academic and industrial research for the mining and oil sands industry to reduce environmental and social impact of tailings management facilities (Fine Tailings Fundamentals Consortium, 1995; Jewell and Fourie, 2006). The dewatering technologies facilitate tailings management to meet the increasing geotechnical performance criteria of tailings depositions during operation and after closure. The geotechnical performance of tailings deposits is paramount for large tailings facilities in regions with high seismic activities (e.g. the Andes in South America). The improvement in geotechnical properties of tailings by dewatering is also critical for the oil sand industry in Alberta, Canada, where mine closure plans require a trafficable surface on the tailings surface in accordance with the Alberta Energy Resources Conservation Board Directive 074 (ERCB, 2009).

Tailings dewatering may be treated in two different and interdependent stages: 1 ) the thickening process using flocculants and other chemical additions; 2) the geotechnical (physical) process by promoting consolidation and drying in the natural environment and/or using enhanced drainage systems consisting of sand and geosynthetic materials. These two dewatering stages are not independent because the chemical additives used in the thickening process may have an effect on the geotechnical properties of the deposited tailings, and the geotechnical criteria may also set requirements for the thickening process. 
Thickened tailings facilities to store over one billion tonnes of tailings have been designed for mining projects in South America, with the heights of the tailings deposits up to several hundred metres (Li et al., 2009). The seismic stability and liquefaction resistance of the tailings is one of the primary design considerations. Li et al. (2009) developed a design approach for the stability of thickened tailings deposits based on critical state soil mechanics theory. The proposed design approach stipulates that the required density of tailings (or its 'initial' void ratio) be achieved through consolidation and drying prior to deposition of a new layer on the tailings beach. This paper discusses the estimation of the initial void ratio of tailings after deposition on a tailings beach in a given thickness as well as after having experienced drying under specific weather conditions. The initial void ratio of tailings immediately following deposition affects the performance of tailings deposits under both static and seismic loading conditions, particularly the postliquefaction stability of tailings deposits. Furthermore, the consolidation and drying behaviour of the tailings during the post deposition period governs the strength gain of the tailings, which is one of the key geotechnical parameters in terms of performance criteria.

This paper presents analysis methods and design tools for the prediction of the initial void ratio and density of tailings following self-weight consolidation and drying for a finite thickness of freshly deposited tailings.

\section{Tailings deposition and design considerations}

In thickened tailings disposal, tailings deposition involves discharging thickened tailings using spigots or a single pipe at selected locations to form a relatively uniform tailings beach in the tailings basin. Once the tailings beach reaches specific elevations, the tailing discharge is moved to another location or the direction of tailings flow is adjusted to fill the tailings basin and to allow for the tailings beach to consolidate and dry (at the same time). Due to the alternating cycles of discharge locations and variations of ore types and mill and thickening processes, the tailings deposit is often stratified and non-homogenous with a highly complex naturally developed constituent matrix and fabric. To achieve operating targets requires detailed deposition planning including the design of discharge systems and tailings transportation pipelines as well as the design of water management facilities. The fresh layer thickness required for geotechnical performance will determine the frequency of switching and raising discharge spigots, which requires significant operating effort and should therefore be minimised.

It is well recognised that drying requires thin layer deposition since the depth of penetration of the drying process is limited due to crust formation at the surface (Abu-Hejleh and Znidarcic, 1995). In semi-arid or arid regions, where it is important or necessary to utilise the natural drying mechanisms to meet design and performance criteria, such as increasing strength to achieve post-seismic stability or increasing average density to meet storage capacity requirements, the crust may need to be ploughed to increase the rate of drying, as is commonly used in red mud management (Cooling, 2007). During design stages, it is necessary to estimate the degree of drying required to achieve a given initial condition and to estimate the drying time and layer thickness for the specific type of tailings and weather conditions consistent with the production schedule and operating effort. A deposition plan needs to be developed so that the freshly deposited tailings layer can be left long enough for consolidation and drying before another layer of tailings is deposited on top. We also need to consider the topographic conditions of disposal areas available and production schedules, which evolve with time during the mine life. The layer thickness and drying period should be optimised to reduce operational effort and costs.

The geotechnical design tools should capture the essential characteristics of the self-weight consolidation and drying behaviour of tailings but the theory should not be too complex for practical applications, since there are many other influencing factors. Since tailings deposition involves a significantly large area, relative to the vertical thickness of each new tailings layer, we can simplify consolidation and drying to a one-dimensional model assuming that moisture can only migrate vertically. Analytical closed form solutions for one-dimensional problems can often be obtained, and they provide an effective yet simple tool for design and operation management. 
After being discharged from pipes or spigots, tailings will undergo three phases of volume change: 1) initial self-weight consolidation; 2) drying; and 3) further consolidation during subsequent deposit cycles. This paper addresses the volume change during the first two phases. The volume change during the third phase is addressed elsewhere (Li et al., 2009).

\section{Previous work on modelling of self-weight consolidation and drying}

The consolidation and evaporative drying behaviour of hydraulically transported fill materials has been extensively studied including studies for tailings (Swarbrick and Fell, 1992; Consoli and Sills, 2000), dredged materials (Krizek et al., 1977; Benson and Sill, 1991; Stark et al., 2005), and phosphate residues (Abu-Hejleb and Znidarcic, 1995). The coupled governing equations for volume change due to self-weight consolidation and drying have been established for both saturated and unsaturated states (e.g. Krizek et al., 1977; Casteleirio et al., 1981; Yao et al., 2001). However, the cyclic consolidation and drying of the tailings during layered deposition is not considered within existing coupled models. The boundary and initial conditions of the tailings changes during deposition cycles are difficult to apply to the coupled equations. Analytical solutions do not exist for the coupled partial differential equations.

Empirical drying models have been proposed (e.g. Swarbrick and Fell, 1992; Stark et al., 2005) but they may not be sufficient for design use. It is challenging to apply the existing models for tailings deposition studies since they do not address all three phases of volume changes during tailings deposition. A new model and approach to capture the volume change of tailings during the mine life is warranted, but it should not be too cumbersome in mathematical or numerical formulation for engineering design.

It is well understood that soils and tailings generally exhibit two stages of evaporation during evaporative drying (Gilliland and Sherwood, 1933; Swarbrick and Fell, 1992). The first stage is at a constant rate of evaporation which may be estimated from pan evaporation (Howell et al., 1983). The potential evaporation is a function of temperature, relative humidity, wind speed, vapour pressure and solar radiation and can be evaluated using the Penman equation (Wilson et al., 1994). During the second stage, the rate of evaporation decreases with time due to the formation of an unsaturated layer and a dramatic decrease in hydraulic conductivity with increasing suction in the crust (Fredlund and Rahardjo, 1993). The crust formation hinders moisture migration from the underlying soil to the surface. Crack formation can extend the first constant rate of the evaporation stage due to the increase in evaporative surface area of the cracks (Abu-Hejleb and Znidarcic, 1995).

The volume change of tailings with time is one of the primary interests for tailings engineers during deposition planning and stability evaluation. The volume change due to consolidation continues over a prolonged period of time as the degree of consolidation approaches $100 \%$. On the other hand, the volume change due to drying diminishes quickly when the soil matric suction overcomes the air entry value of the tailings. Theoretical models must consider the reduction in the rate of water loss during drying and potential exposure of sulphide minerals to oxygen.

\section{$4 \quad$ Modelling of initial consolidation and drying}

After discharge, thickened tailings will initially exhibit flow behaviour on a tailings beach (Li, 2011). Immediately after the tailings flow comes to rest on the tailings beach, the tailings will undergo initial selfweight consolidation. Continuous discharge increases the thickness of the freshly deposited tailings and water will continuously drain upwards to the surface (drainage is primarily upwards because that is the shortest drainage path). Therefore the initial consolidation can be approximately treated as a onedimensional and one-way drainage problem.

After the discharge is moved, the initial self-weight consolidation will continue and there will be a relatively large amount of water expelled out of the tailings due to the high water content of tailings slurry. The rate of water coming to the surface from self-weight consolidation is generally greater than evaporation rates and evaporation only starts to have an effect on the void ratio when the initial self-weight consolidation of 
the tailings is largely complete. Dewatering from initial self-weight consolidation usually takes days while further dewatering from drying can take months, depending upon the layer thickness. Therefore, it is a reasonable approximation to decouple the physical processes of consolidation and drying for theoretical modelling. In other words, the transient drying can be solved independently by assuming that the further relatively small degree of self-weight consolidation (if it even exists) has a negligible effect on the evaporation. This assumption is still valid even if the further consolidation exists during the early stage of drying at a constant potential evaporation rate.

\section{1 Initial consolidation of tailings - large deformation modelling}

During self-weight consolidation, soils will undergo large deformations because the initial effective stress is low and void ratio is high in the early stage of development of soil matrix (Been and Sills, 1981). During tailings deposition, the drainage path increases as thickness of the deposit gradually increases. Therefore, for self-weight consolidation problems, the conventional Terzaghi consolidation theory becomes invalid due to the inherent assumption of infinitesimal strains and fixed drainage paths. Gibson et al. (1967) developed a finite strain consolidation theory for self-weight consolidation with the following governing equation:

$$
\frac{\partial e}{\partial t}=-\frac{\partial}{\partial z}\left[\frac{k}{\rho_{f}(1+e)} \frac{d \sigma^{\prime}}{d e} \frac{\partial e}{\partial z}\right]-\left(\rho_{s}-\rho_{f}\right) \frac{d}{d e}\left(\frac{k}{\rho_{f}(1+e)}\right) \frac{\partial e}{\partial z}
$$

where:

e $\quad=\quad$ void ratio.

$\mathrm{z}=$ soil thickness (material coordinate).

$\sigma^{\prime} \quad=\quad$ effective stress.

$\mathrm{k}=$ hydraulic conductivity (varying with e).

$\rho_{s} \quad=\quad$ unit weight of the tailings particles.

$\rho_{f} \quad=\quad$ unit weight of the pore fluid.

For a constant rate of rise and a one way drainage boundary condition, Lee and Sills (1981) developed analytical closed form solutions for the void ratio change at any time and any depth as follows.

$$
\Delta e(y, T)=\frac{\beta c_{v}}{m} T\left[\left(\frac{T}{\pi}\right)^{1 / 2} \exp \left(\frac{-y^{2} T}{4}\right) \int_{0}^{\infty} \xi \tanh \left(\frac{\xi T}{2}\right) \cosh \left(\frac{\xi y T}{2}\right) \exp \left(\frac{-\xi^{2} T}{4}\right) d \xi-y\right]
$$

where:

$T=$ time factor.

$c_{v}=$ consolidation coefficient.

$y=\quad$ depth of tailings in Lagrangian coordinates.

$\mathrm{m} \quad=\quad$ rate of rise.

$\beta=$ normalised compressibility.

The void ratio change due to consolidation after deposition is solved as the following:

$$
\Delta e(y, T)=\beta m t\left[1-y-2 \sum_{n} c_{n} \cos \left[\left(\frac{2 n-1}{2}\right) \pi y\right] \exp \left[-\left(\frac{2 n-1}{2}\right)^{2} \pi^{2} T\right]\right]
$$


The Fourier coefficients $c_{n}$ are a function of the time factor and depth; $n=0,1,2, \ldots$

In the above solutions, it is assumed that the stiffness of soils (or deposited tailings) is a constant. The Lee and Sills (1981) solutions can be modified to include the nonlinear compressibility of the tailings during consolidation by replacing the stiffness coefficient by a power function using the following equation:

$$
e=A \sigma^{B}
$$

The coefficients A and B can be obtained from fitting the settlement curve obtained using Equations (2) and (3).

The coefficient of consolidation $c_{v}$ is a function of hydraulic conductivity and compressibility, which are highly non-linear. However, the coefficient of consolidation is close to constant during the initial self-weight consolidation. The estimation of the consolidation coefficient can be carried out by comparison of model predicted settlements with measured settlements (Been and Sills, 1981).

A Fortran program SWCONS was developed to carry out integrations for Equation (2) and to numerically capture the non-linear compressibility of the problem. The rate of water release due to consolidation can be calculated for the entire consolidation stage. During the early stage of the consolidation, the rate of water release will be greater than the evaporation rates and water will run off the tailings surface. The effect of evaporation only becomes significant when the potential evaporation is greater than the rate of migration of consolidation water to the surface. This determines the onset of drying and the need for modelling of drying.

\section{2 Modelling of evaporative drying}

It has been demonstrated (Gilliland and Sherwood, 1933; Richards, 1965; Casteleiro et al., 1981; Benson and Sill, 1991; Morris et al., 2007) that the soil-moisture transpiration in unsaturated fine-grained soils is dominated by a diffusion mechanism when the soil is subjected to evaporative drying only. Water vapour in the matrix of unsaturated fine-grained soils is negligible. Gilliland and Sherwood (1933) established a diffusion equation for drying of soils in the form of the moisture concentration, defined as the ratio of the mass of the water over the volume of the soil. Benson and Sill (1991) adopted these equations in the form of volumetric moisture content, defined as the volume of water over the solids, and further developed closed form solutions for the governing equation using a parabolic approximation. Benson and Sill (1991) validated their solutions using dredged materials from five different sites and demonstrated that the rate of the actual evaporation predicted by the model had good agreement with the measured actual evaporation for the five different fine-grained soils.

Following the framework established by Gilliland and Sherwood (1933) and Benson and Sill (1991), the following one-dimensional diffusion equation is proposed to describe moisture migration during evaporative drying of fine-grained soils and tailings:

$$
\frac{\partial \theta}{\partial t}=D \frac{\partial^{2} \theta}{\partial z^{2}}
$$

where:

$\theta=\quad$ volumetric water content defined as the ratio of the volume of water/the total volume of the soil or tailings.

$t=$ drying time.

$\gamma=$ unit weight of the fluid.

$z=$ depth in the vertical direction.

$D=\quad$ coefficient of drying (volumetric water diffusivity). 
Similar to the coefficient of consolidation of soils, the coefficient of drying is relatively constant in comparison to the variation of hydraulic conductivity during drying. The coefficient of drying of the soil can be determining by curve-fitting of the drying curve obtained in the laboratory using pan or column drying tests. If the sample is sufficiently large, the volume change will cause cracks which have an effect on the volumetric water content versus time curve due to evaporation from crack walls. Cracking in soils and tailings is a highly complex problem. Modelling cracks requires a separate theoretical framework (Morris et al., 1992; Ayad et al., 1997) and is not considered here. However, the effect of the cracks can be approximated through the measurement of the drying coefficient using sufficiently large and thick samples in which cracks would be generated.

Similar to the governing equation for the Terzaghi consolidation theory, a non-dimensional form of Equation (5) can be used:

$$
\frac{\partial \Theta}{\partial T}=\frac{\partial^{2} \Theta}{\partial Z^{2}}
$$

where:

$\Theta=$ normalised moisture content, $\theta / \theta_{0}(\theta=$ initial moisture content $)$.

$T=$ time factor, $\mathrm{tD} / \mathrm{H}^{2}$.

$Z=$ geometry parameter, $\mathrm{z} / \mathrm{H}$.

An integral method was used to obtain closed form solutions to this governing equation. Integral methods have been used to solve the Terzaghi consolidation equation (Craig, 1987) and a drying equation (Benson and Sill, 1991). Integrating Equation (6) with respect to the depth from 0 to the bottom of the soil layer, $H$, and applying the Leibniz's rule for a finite region, we obtain:

$$
\frac{d}{d T} \int_{0}^{H} \Theta d Z=\left.\frac{\partial \Theta}{\partial Z}\right|_{0} ^{H}
$$

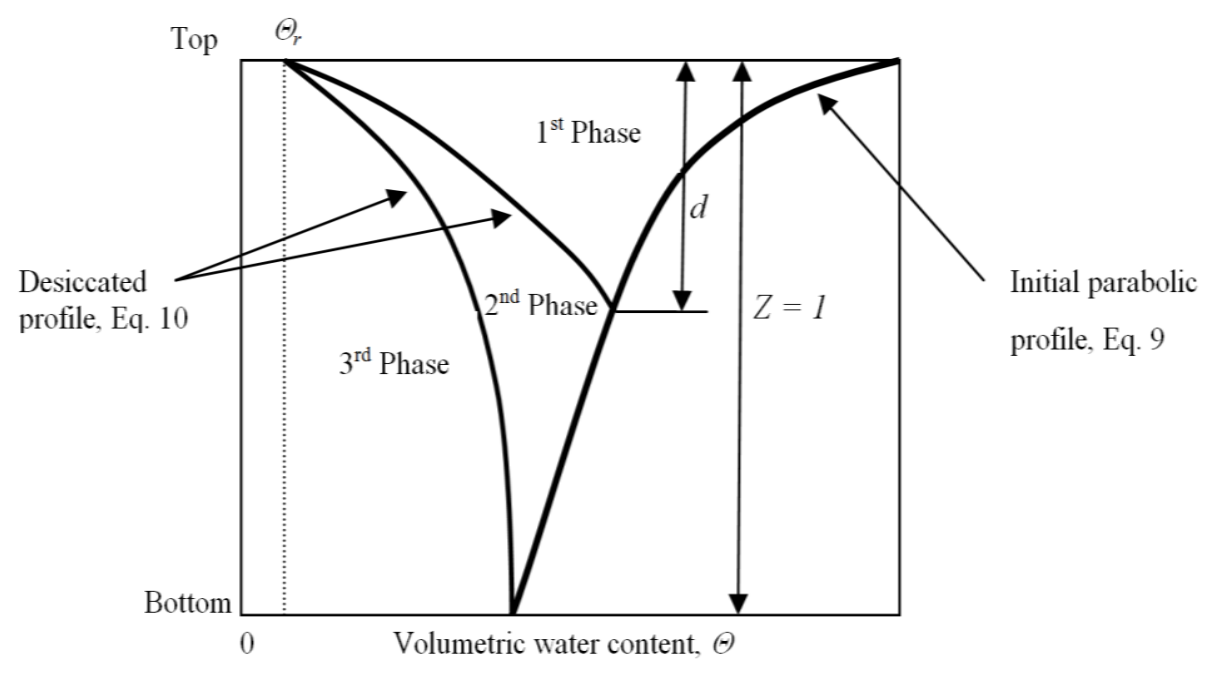

Figure 1 Simplification of the drying phases following self-weight consolidation

Figure 1 illustrates the three phases of drying of a tailings profile after self-weight consolidation. The initial volumetric water content is not a constant value, and the profile after self-weight consolidation is approximated as a parabolic distribution with depth:

$$
\Theta_{0}=1+A_{1} Z+A_{2} Z^{2}
$$


Within the normalised penetration depth, $d=h / H$, of the zone of drying, the moisture profile is approximated using a parabolic function:

$$
\Theta(d, T)=C_{0}+C_{1} \frac{Z}{d}+C_{2}\left[\frac{Z}{d}\right]^{2}
$$

During the first phase of drying, the rate of evaporation is constant and equals the potential evaporation. The end of this phase occurs when the surface of the material has become unsaturated and reached the residual moisture content, $\theta_{r}$. Initial and boundary conditions are:

Table 1 Initial and boundary conditions for different drying phases

\begin{tabular}{ccc}
$\begin{array}{c}\text { 1st Phase } \\
\text { Constant Rate }\end{array}$ & $\begin{array}{c}\text { 2nd Phase } \\
\text { Falling Rate }\end{array}$ & $\begin{array}{c}\text { 3rd Phase } \\
\text { Drying of the } \\
\text { Entire Layer }\end{array}$ \\
\hline$\left.\frac{\partial \Theta}{\partial Z}\right|_{Z=d}=0$ & $\left.\frac{\partial \Theta}{\partial Z}\right|_{Z=d}=0$ & $\left.\frac{\partial \Theta}{\partial Z}\right|_{Z=1}=0$ \\
$\Theta(Z, T)=1$ for $Z \geq d$ & $\Theta(Z, T)=1$ for $Z \geq d$ & $\Theta\left(1, T_{b}\right)=\Theta\left(1, T_{c r}\right)$ \\
$\left.\frac{\partial \theta}{\partial Z}\right|_{Z=0}=\frac{E_{p}}{D}$ & $\Theta(0, T)=\Theta_{r}$ & $\Theta(0, T)=\Theta_{r}$ \\
\hline
\end{tabular}

where:

$E_{P} \quad=\quad$ potential evaporation rate.

$\Theta_{\mathrm{r}} \quad=\theta / \theta_{\mathrm{r}}$ normalised residual moisture content.

$T_{c r}=$ time factor when the falling rate evaporation starts.

$T_{b}=$ time factor when potential evaporation reaches the bottom of the soil or tailings layers.

The potential evaporation rate can be estimated from the pan evaporation rate for a specific site or weather conditions or using the Penman equation (Wilson et al., 1994). Applying the above initial and boundary conditions, the following closed form solutions for the volumetric water content can be derived:

$$
\Theta=\Theta_{0}-\frac{E_{p} H}{\theta_{0}}\left[\frac{1}{2}-\left(\frac{Z}{d}\right)+\frac{1}{2}\left(\frac{Z}{d}\right)^{2}\right]
$$

The drying penetration depth, $d$, is evaluated by substituting Equation (9) into the governing Equation (7), which yields a complicated equation with many terms related to the initial moisture parabolic function. To simplify the solution, we can assume a uniform initial moisture profile with an average value of the parabolic distribution and the following equation is obtained:

$$
d=\sqrt{6 T}
$$

From Equations (9) and (10), the critical time factor, $T_{c r}$, can be solved from $\Theta\left(0, T_{c r}\right)=\Theta_{r}$ :

$$
T_{c r}=\frac{2}{3}\left(\frac{\theta_{0} D}{E_{p} H}\right)^{2}\left(1-\Theta_{r}\right)^{2}
$$

Once the drying reaches the second phase, the moisture content is obtained from the following equation:

$$
\Theta=\Theta_{\mathrm{r}}+2\left(\Theta_{0}-\Theta_{\mathrm{r}}\right)\left[\left(\frac{\mathrm{Z}}{\mathrm{d}}\right)-\frac{1}{2}\left(\frac{\mathrm{Z}}{\mathrm{d}}\right)^{2}\right]
$$

where: $\mathrm{d}=\sqrt{6\left(2 T-T_{c r}\right)}$ when $\mathrm{T}>\mathrm{T}_{\text {cr }}$. 
After the drying reaches the bottom of the layer (i.e. the third phase), the moisture content is determined as:

$$
\Theta=\Theta_{r}+2\left(\Theta_{0}-\Theta_{r}\right)\left(Z-\frac{1}{2} Z^{2}\right) \exp \left\lceil-3\left(T-T_{b}\right)\right\rceil
$$

where:

$T_{b}=1 / 12+1 / 2 T_{c r}$, time factor when drying reaches the bottom.

The volumetric water content at any time and any point in the soil layer can be obtained by combining Equations (10), (13) and (14). The constitutive relations can be written in terms of soil-water characteristic curves (SWCC) (Fredlund, 2006). With respect to volume change due to suction, the compressibility of the soil when approaching the shrinkage limit can be represented using the water storage function, $m_{2}{ }^{w}$, in the $\theta-\psi$ space (Fredlund and Rahardjo, 1993). The SWCC can be measured in the laboratory and curve fitted using the equation proposed by Fredlund and Xing (1994):

$$
\theta=C \theta_{r}\left[\frac{1}{\ln \left[e+(\psi / a)^{n}\right]}\right]^{m}
$$

where:

$$
\begin{array}{ll}
\psi & =\text { suction. } \\
a, n, m= & \text { three parameters that describe the shape of the soil-water characteristic curve. } \\
\mathrm{C} & =\text { a correction factor for zero water content at an extreme value of suction. }
\end{array}
$$

During the drying process, the volume change (void ratio) will be proportional to the moisture change when the degree of saturation is $100 \%$. However, the volume change diminishes when the soil starts to become unsaturated because air starts to fill the voids. This relation can be expressed using a shrinkage curve (Fredlund at el., 2002). Both the SWCC and shrinkage curves for a specific soil can be measured in a laboratory. The instantaneous total volume should be used to determine the SWCC when the volume change is substantial (Fredlund et al., 2011). The maximum volume decrease of the soil due to evaporative drying is presented using the shrinkage limit void ratio, $e_{s}$. Based on the SWCC and shrinkage curve, the relation between the degree of saturation and suction can be evaluated. The void ratio and gravimetric water content are readily obtained using phase relations.

There are many techniques that are available for the determination of the diffusivity (drying coefficient) of soils (e.g. Richards, 1965; Benson and Sill, 1991; Swarbrick and Fell, 1992). It is most accurate to backcalculate the drying coefficient through curve-fitting the drying curve obtained from a pan or column drying tests. Computer software EVDRY was developed to evaluate volume change of the tailings and actual evaporation based on the proposed approach and approximate solutions described above. The rate of the actual evaporation can be evaluated from the decrease in volumetric water content for the entire layer.

\section{$5 \quad$ Model verification}

Both SWCONS and EVDRY software programs were verified using the results of laboratory tests. Self-weight consolidation tests were carried out using a $1 \mathrm{~m}$ high and $100 \mathrm{~mm}$ diameter column equipped with pore pressure ports and sampling ports as shown in Figure 2(a). Pressure transducers connected to the pore pressure ports were calibrated to read to $0.1 \mathrm{kPa}$ resolution from $0-800 \mathrm{kPa}$. During the tests, the consolidation settlement and pore pressure were measured. Drying tests were carried out using $20-80 \mathrm{~cm}$ high drying columns $150 \mathrm{~mm}$ in diameter and equipped with tensiometers (Soilmoisture Probe 2100F), Figure 2(b). During drying tests, potential evaporation, actual evaporation, settlement and suction were measured. 


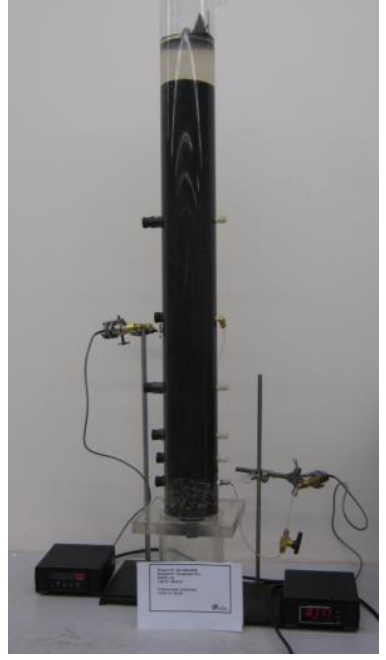

(a)

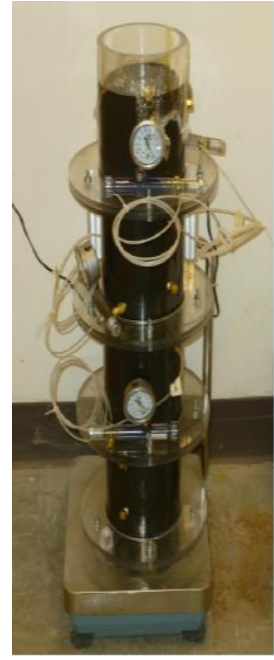

(b)

Figure 2 Laboratory setup for (a) self-weight consolidation tests; and (b) column drying tests

The model verification was a comparison of the predicted and actual volume (settlement) change and evaporation. Once verified, the proposed models can be used to evaluate the initial void ratio and in situ density as well as water loss for water balance analyses.

\section{1 Gold and copper tailings}

A series of self-weight consolidation and column drying tests was carried out using gold and copper tailings to investigate the initial consolidation and drying behaviour of the tailings discharged on a tailings beach. The tailings streams were generated from an oxide plant and a sulphide plant, respectively. Subsequently the two streams of tailings were blended in a thickener. The underflow samples of the thickener were prepared at a solids content ranging from $55-70 \%$ solids for the laboratory testing program. The tailings were classified as non-plastic silt with $10 \%$ sand and $12 \%$ clay size particles (Figure 3 ). The specific gravity of the solid particles was 3.1 .

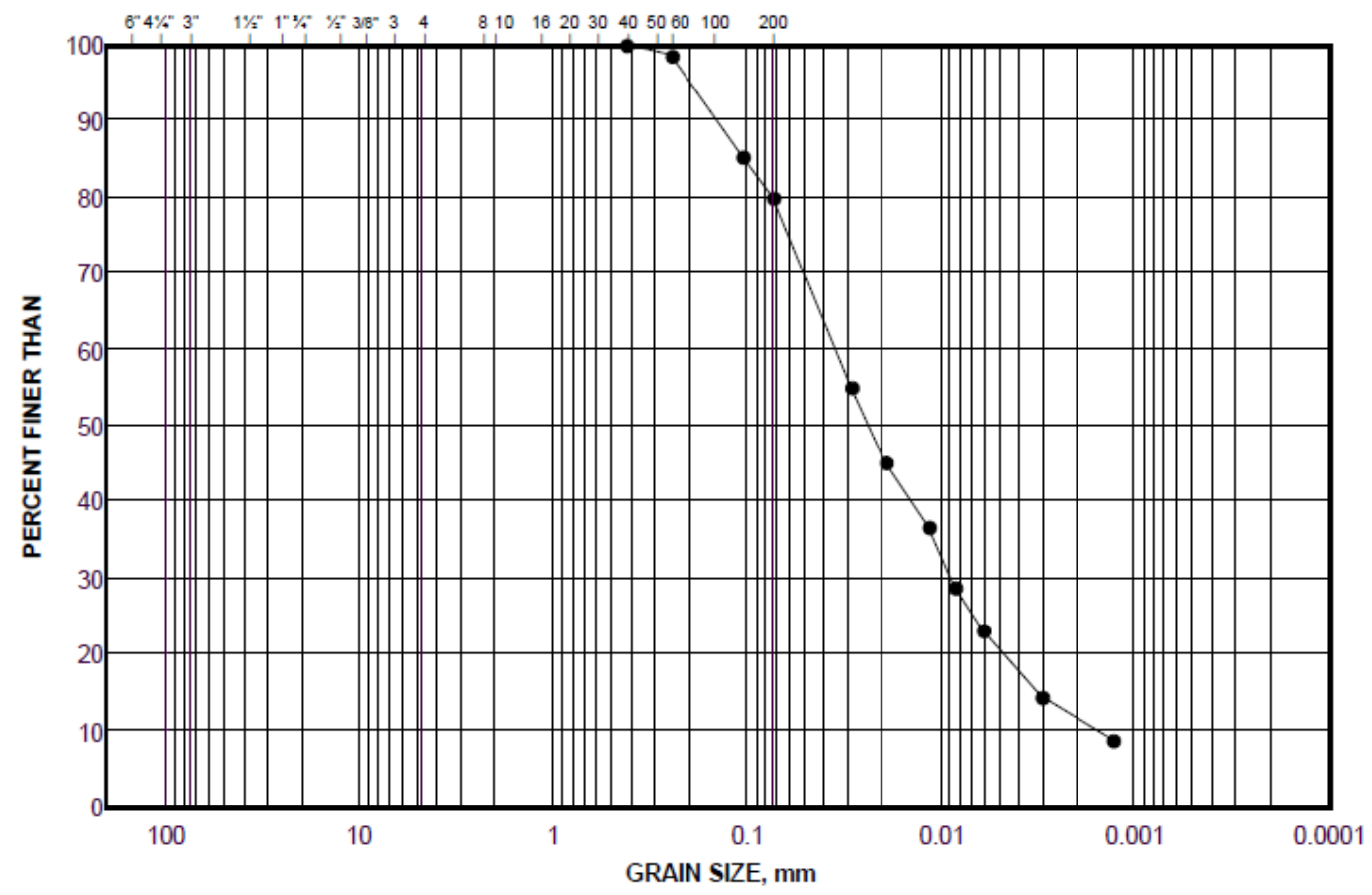

Figure 3 Grain size distribution of the gold and copper tailings 


\subsubsection{Self-weight consolidation}

Figures 4 and 5 present results of the self-weight consolidation and the model back-analyses through curvefitting. For this test, the initial solids content of the tailings was prepared at $55 \%$. The consolidation coefficient from this curve-fitting was $0.027 \mathrm{~m}^{2} /$ day and the compressibility coefficients $A$ and B were 1.77 and -0.16 , respectively. As is shown in Figure 4 , the predicted settlement (volume change) closely matched the measured settlement curve. The excess pore pressures were measured at the bottom and the middle height of the column. The model reasonably predicted the rate of the dissipation of the excess pore pressures at different heights as shown in Figure 5. Six samples were taken for moisture determination at the end of the consolidation tests and the results were compared with the model calculated moisture profile as shown in Figure 6. The measured high moisture content at the surface was due to dilution of the tailings slurry at zero effective stress by water that migrated to the surface during sample preparation.

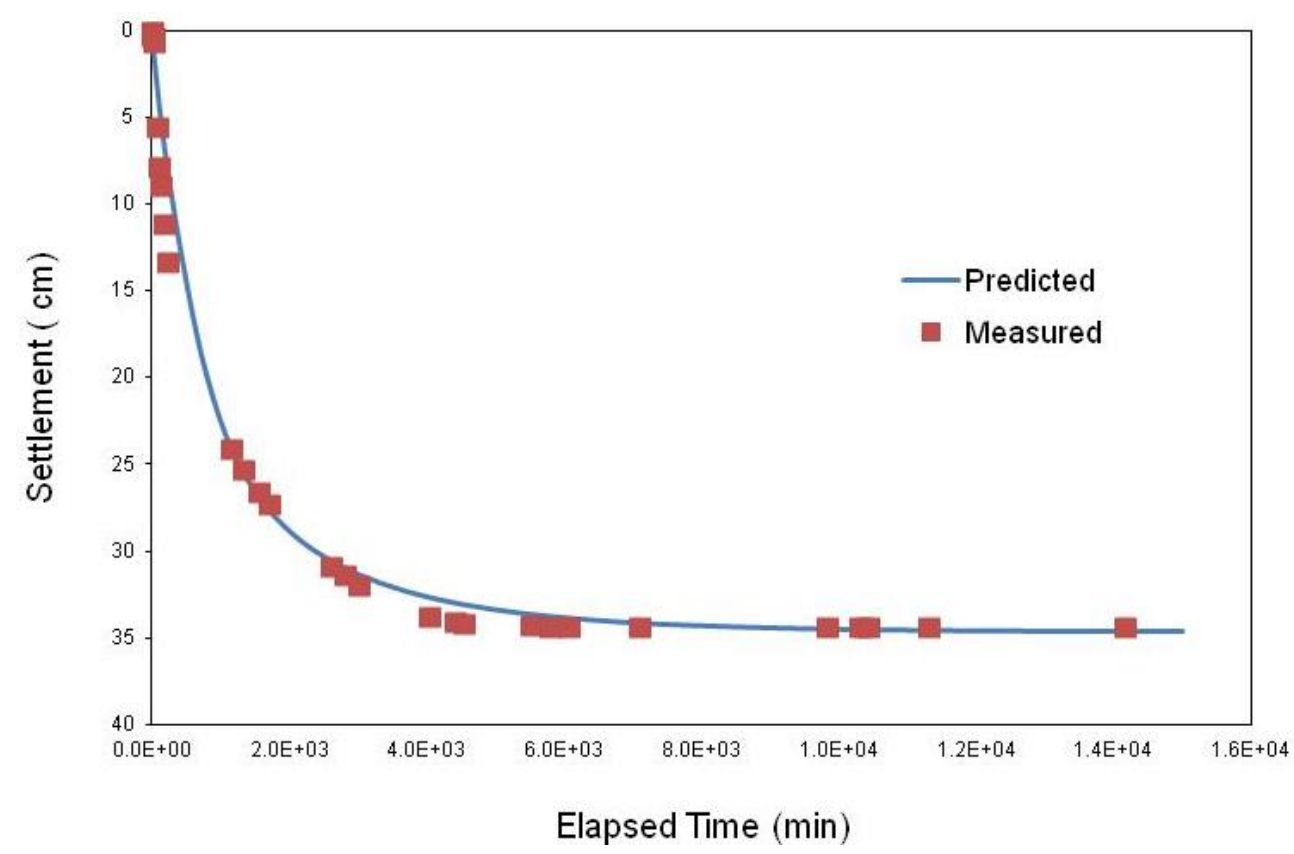

Figure 4 Prediction of the settlement and volume change during self-weight consolidation 


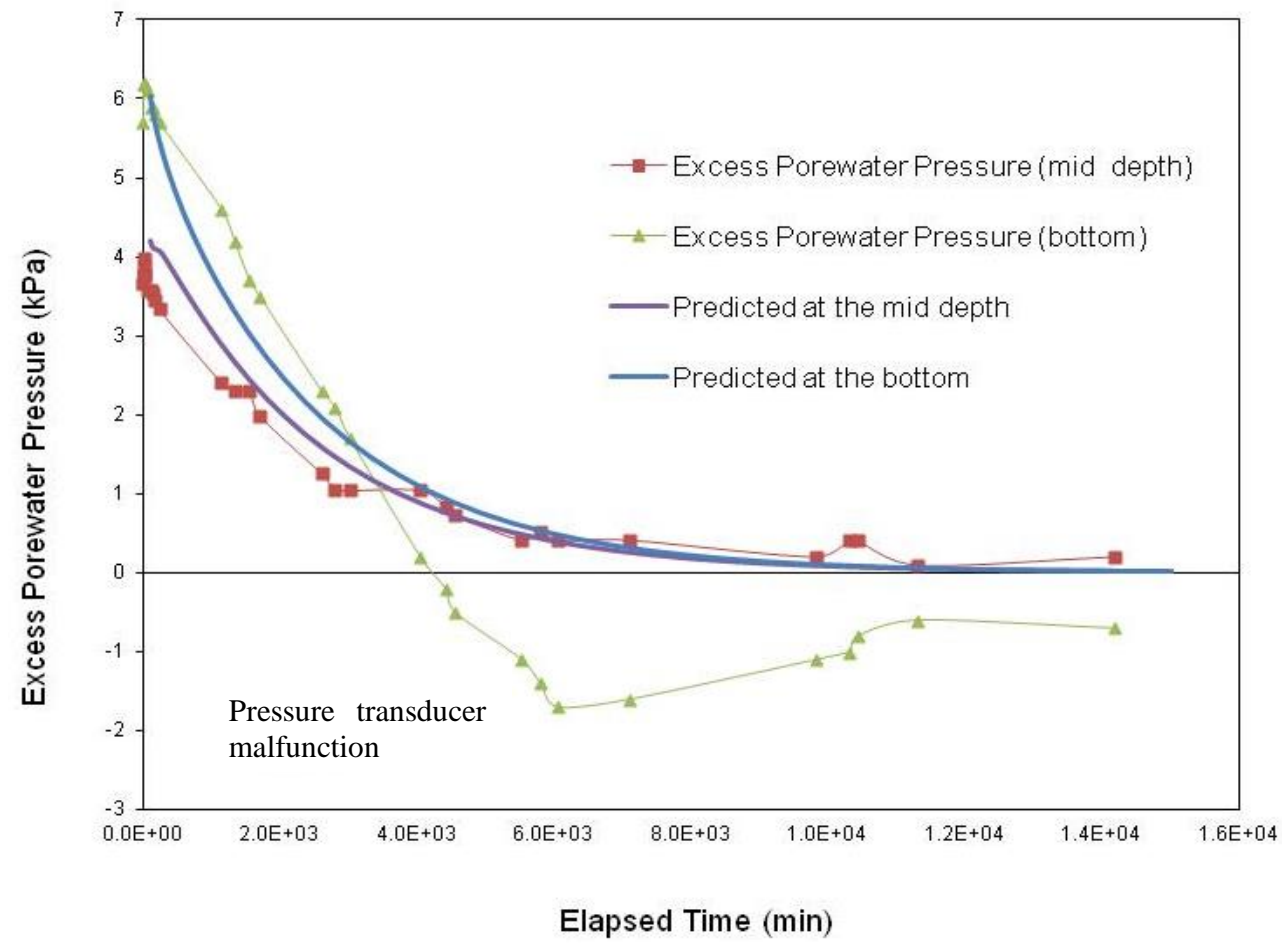

Figure 5 Predictions of the excess pore pressures

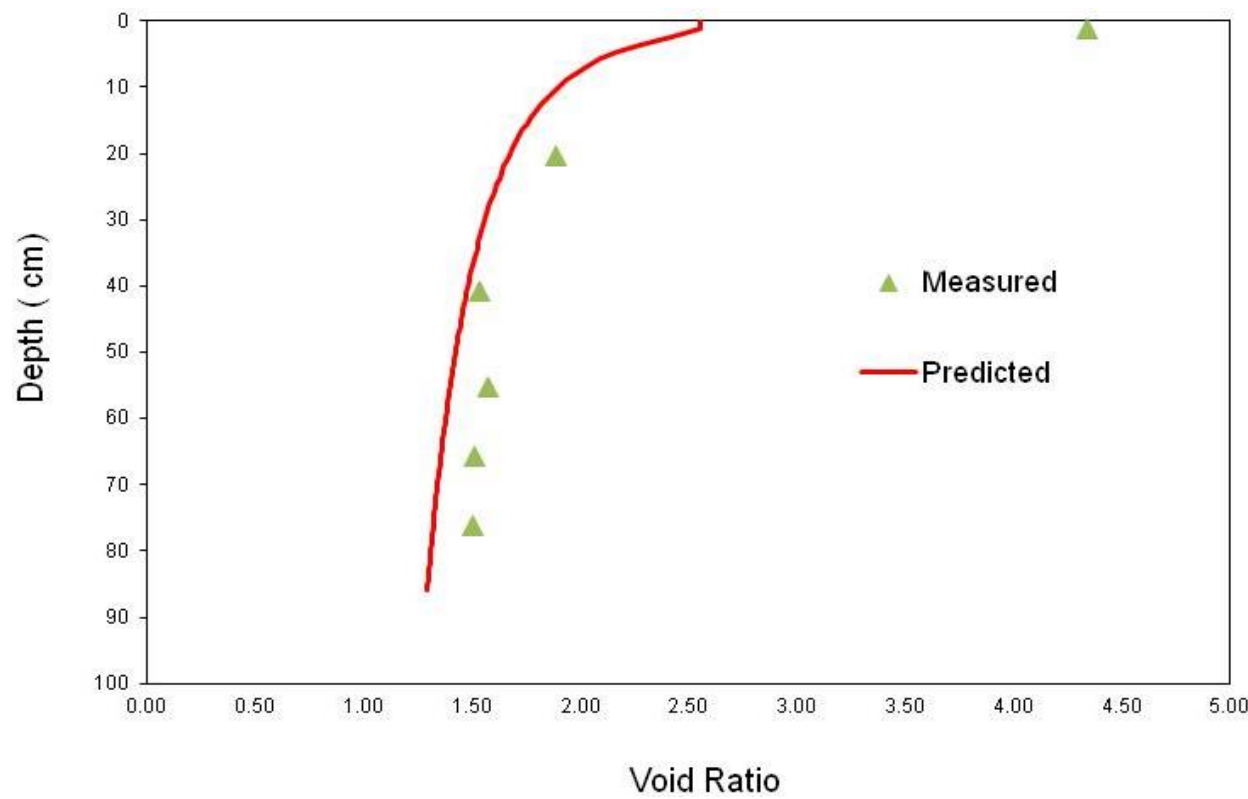

Figure 6 Prediction of the final moisture content profile for self-weight consolidation

\subsubsection{Self-weight consolidation and drying}

The gold/copper tailings were also prepared at $70 \%$ solids and continuous initial self-weight consolidation and drying tests were conducted under the laboratory room temperature and humidity conditions. During the continuous testing, water that accumulated on the surface was removed using a syringe on a daily basis. The potential evaporation was approximately determined using a water column with the same diameter as the drying column. The unsaturated soil properties were determined using the soil water characteristic curve and the shrinkage curve presented in Figure 7. The air entry value measured was approximately $70 \mathrm{kPa}$ and shrinkage limit void ratio was 0.73 for the sample with initial void ratio of 1.45 . 


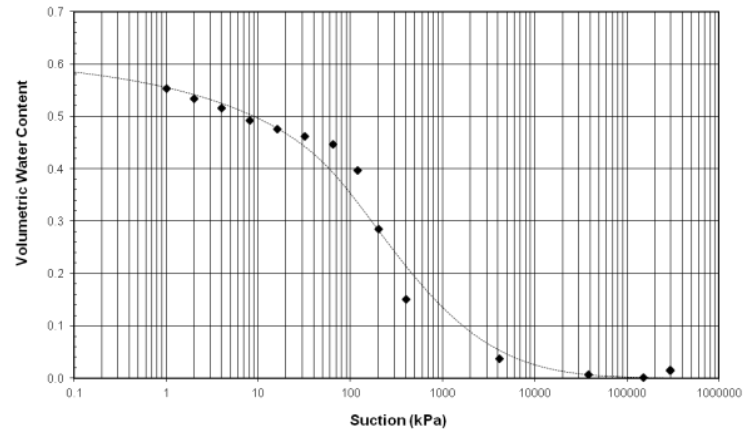

(a)

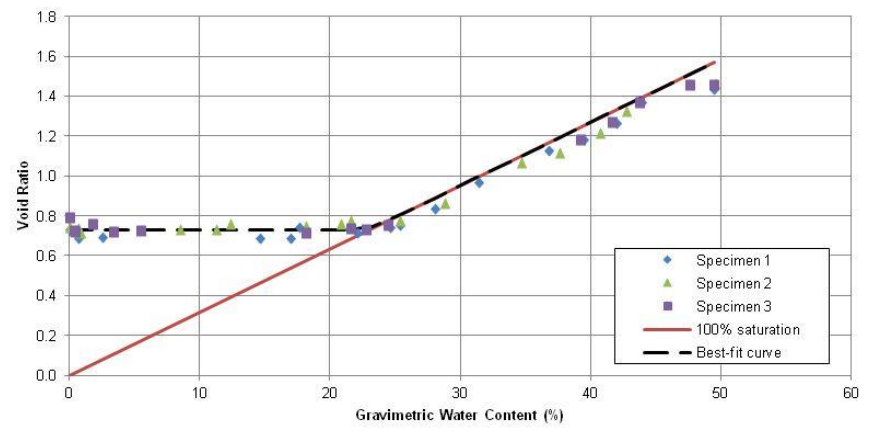

(b)

Figure 7 (a) Measured SWCC; and (b) shrinkage curves of the gold/copper tailings

The first column drying test was carried out using a $20 \mathrm{~cm}$ high sample to measure the consolidation coefficient, compressibility parameters and drying coefficient. The second test was carried out using a $60 \mathrm{~cm}$ high sample. The consolidation and drying properties obtained from the first test were used to predict the volume change and actual evaporation of the second test. Figure 8 shows the fitted settlement curve using a consolidation coefficient of $0.01 \mathrm{~m}^{2} /$ day and compressibility coefficients A and B of 1.15 and -0.054 , respectively. During the evaporation stage, the average potential evaporation was $2.2 \mathrm{~mm}$. Through curve-fitting of the drying curve shown in Figure 9 , the drying coefficient of $15 \mathrm{~cm}^{2} /$ day was obtained.

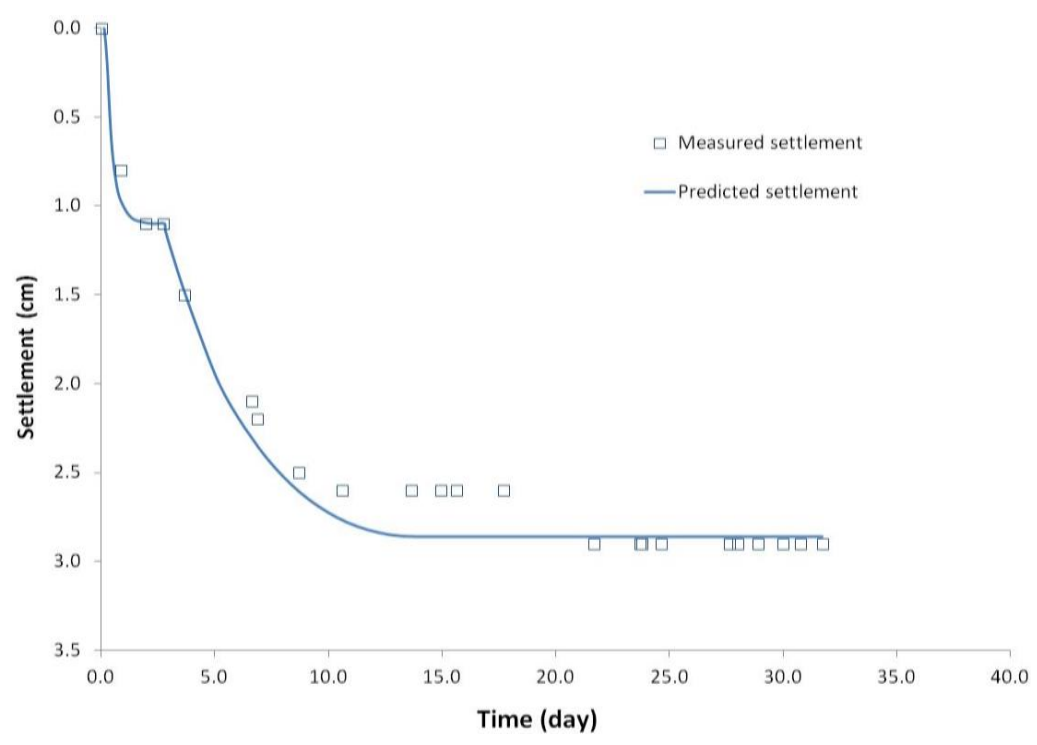

Figure 8 Continuous settlement of the $20 \mathrm{~cm}$ high sample during the initial self-weight consolidation and drying 


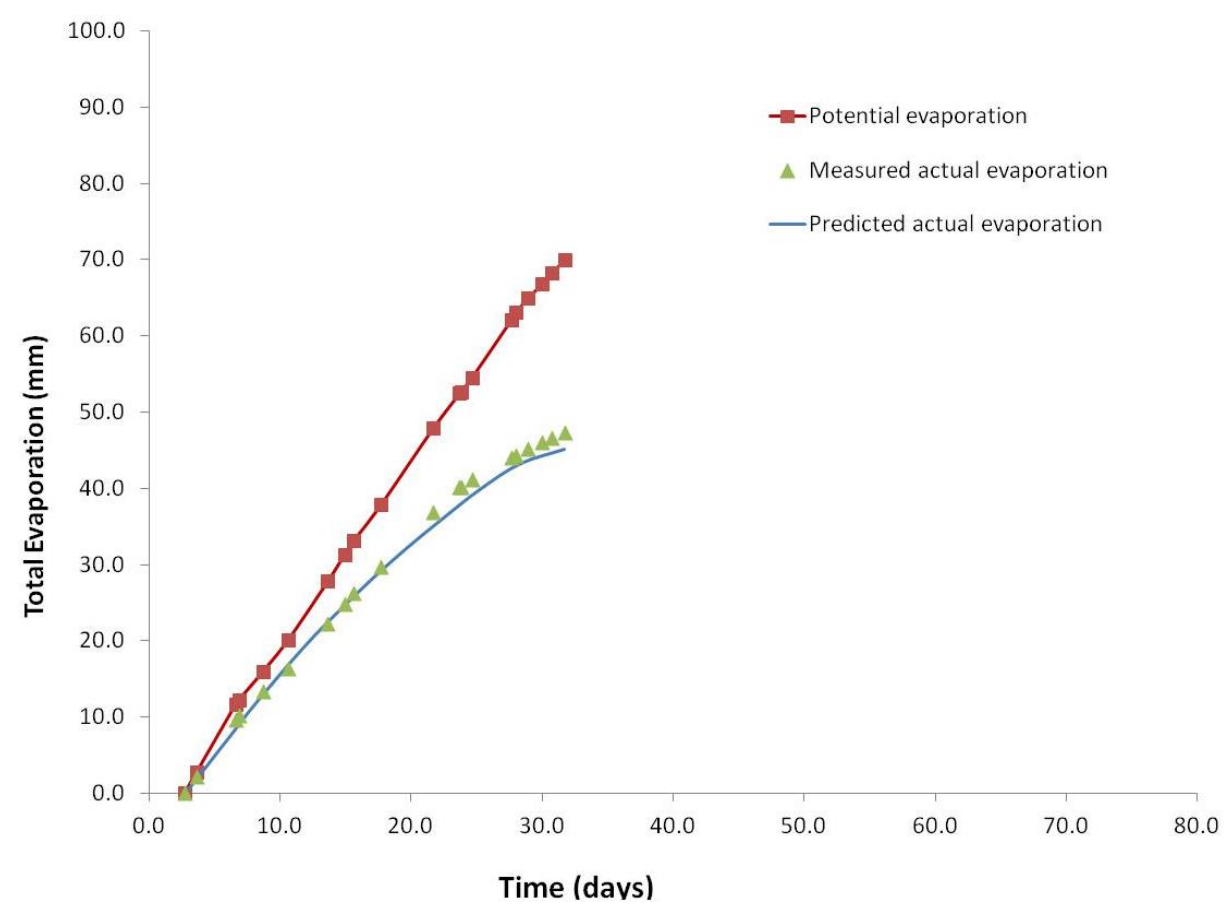

Figure 9 Potential, actual and predicted evaporation of $20 \mathrm{~cm}$ high sample in the lab

Using the soil parameters obtained from the first test, the predicted settlement curve and evaporation curve for the second test are presented on Figures 10 and 11. The modelling results demonstrate that the models produced excellent agreement for both the rate of volume change and rate of evaporation for the $60 \mathrm{~cm}$ high sample. The predicted suction pressure at $5 \mathrm{~cm}$ below the surface is also compared with the measured suction pressure in Figure 12.

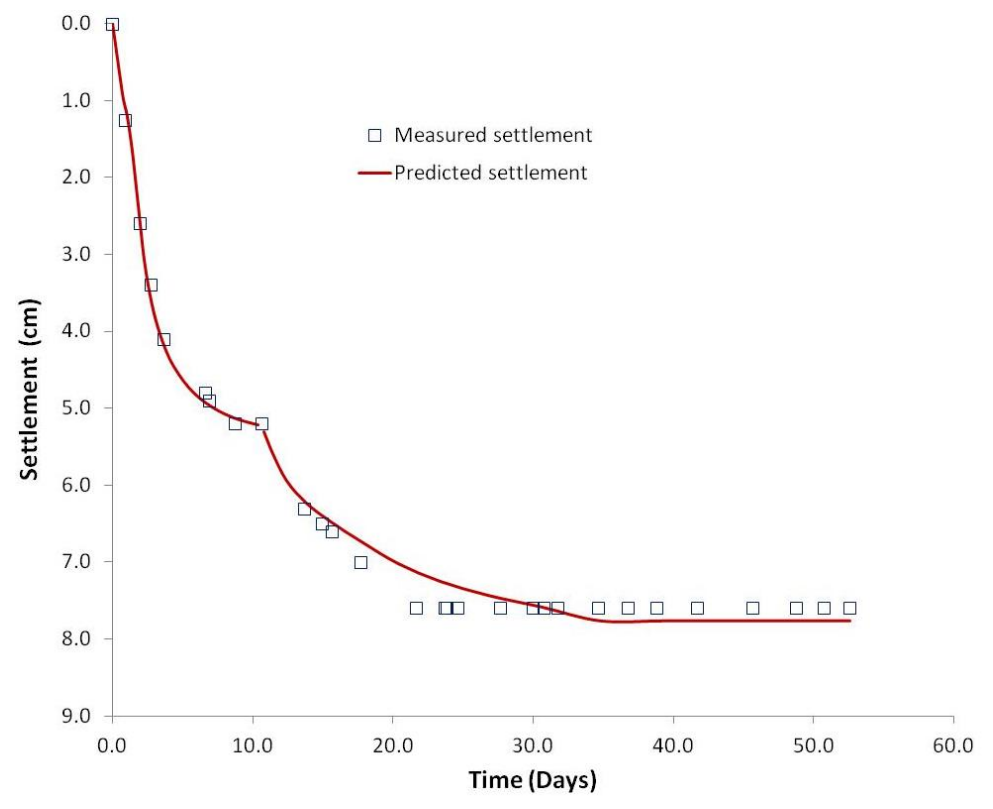

Figure 10 Measured and predicted settlement curve for $60 \mathrm{~cm}$ high sample 


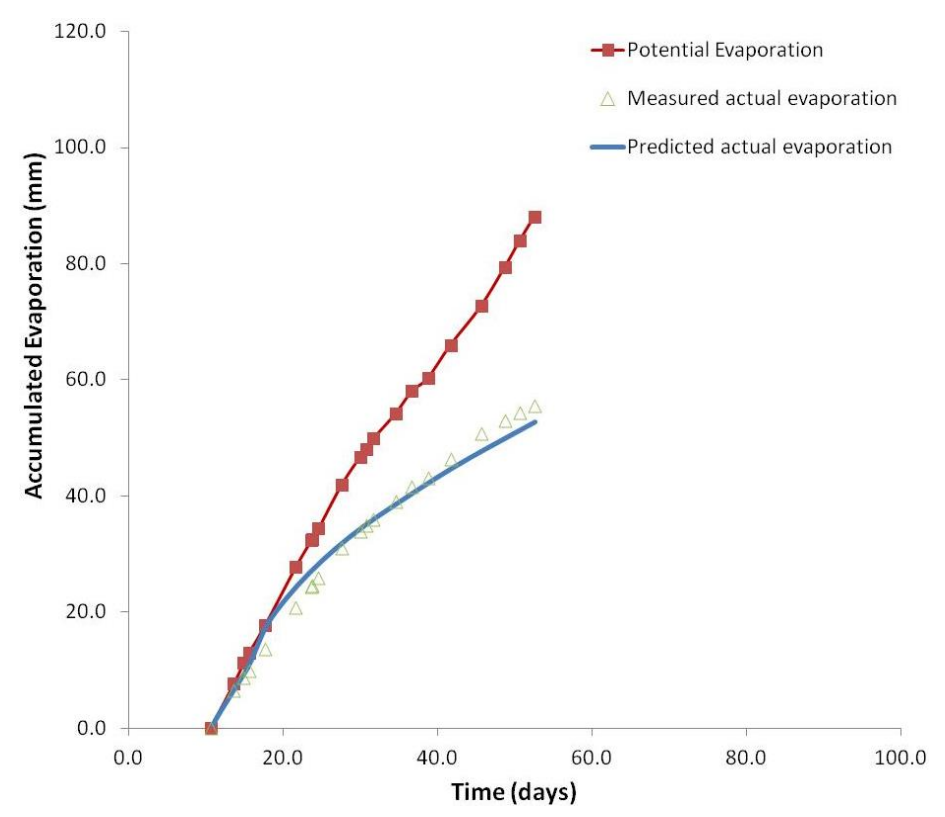

Figure 11 Measured and predicted evaporation rates for the $60 \mathrm{~cm}$ high sample

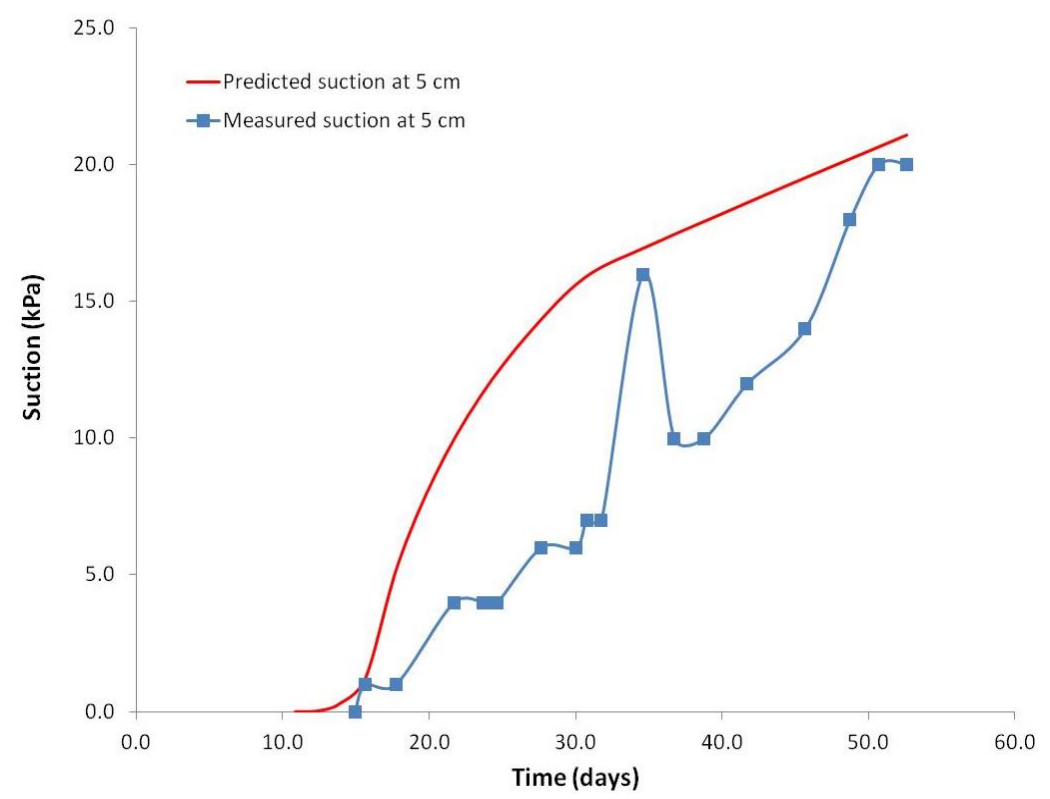

Figure 12 Measured and predicted suction pressures for $60 \mathrm{~cm}$ high sample

\section{2 0il sands tailings}

The proposed self-weight consolidation and drying models were also verified using samples of oil sands tailings. The oil sands tailings tested were non-plastic tailings. An $80 \mathrm{~cm}$ high column was used for the selfweight consolidation and subsequent drying test over a period of 63 days. The drying test was initiated after the self-weight consolidation was completed by decanting consolidation water from the top of the sample. Both the soil-water characteristics of the tailings and the shrinkage curve were obtained through laboratory tests. The air entry value was approximately $10 \mathrm{kPa}$ and shrinkage limit void ratio was about 1.7. Modelling analyses were carried out using SWCONS and EVDRY for the consolidation and drying stages respectively. The predicted settlement is presented in Figure 13. The consolidation and drying settlement was about $17.6 \mathrm{~cm}$ and $5.2 \mathrm{~cm}$, which represents 22 and $7 \%$ of volume change during the two stages, respectively. 


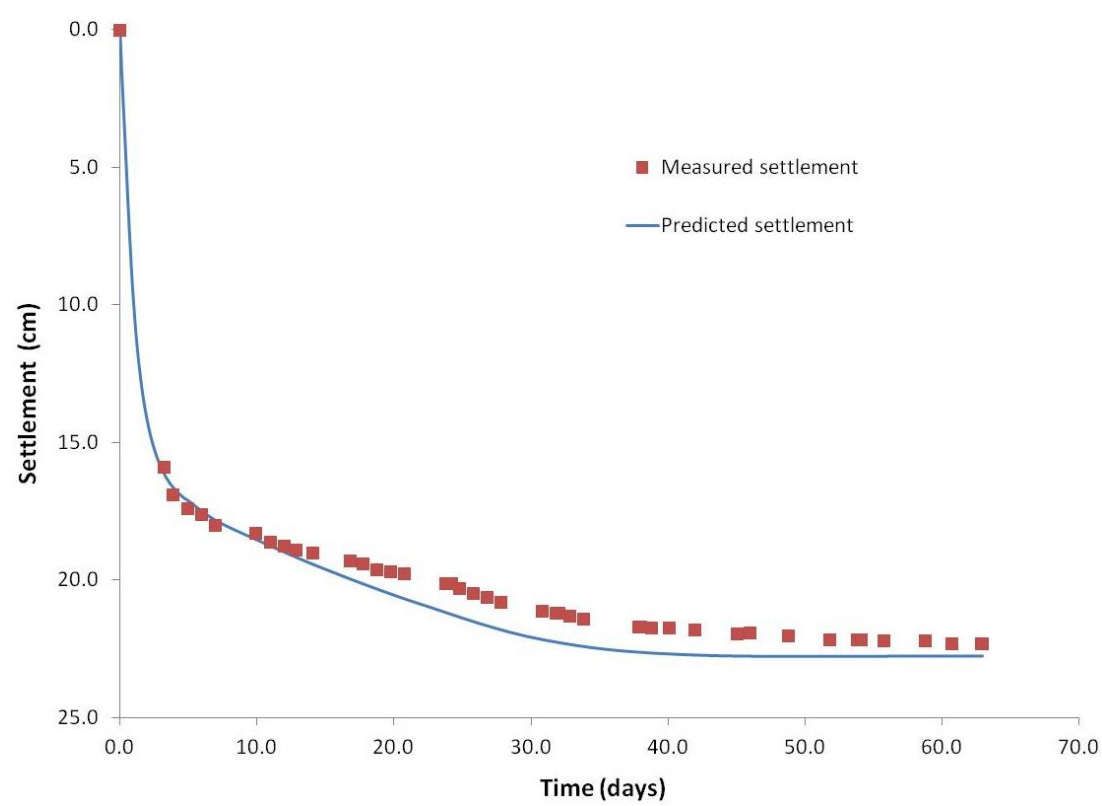

Figure 13 Comparison of the measured and predicted settlement curve for the oil sands tailings

During the drying test period, the average potential evaporation was approximately $2 \mathrm{~mm}$. Figure 14 shows that the model prediction matched the actual evaporation at the end of the test period with a slight overestimation during the early evaporation stage. The predicted moisture content profile at the end of the test is shown in Figure 15 in comparison to the initial condition and the moisture content profile at the end of consolidation. As is shown in Figure 15, the model can predict the crust formation of the tailings during drying as illustrated by the moisture content profile. For this case, the gravimetric water content decreased dramatically in the upper $20 \mathrm{~cm}$. After 63 days, the drying appeared to have just reached the bottom of the column. The predicted gravimetric water content profile agreed reasonably well with the measured profile, depicting three different zones: the upper crust with significantly lower moisture content, the middle zone with a relatively uniform water content, and the lower zone with water content decreasing with depth due to the effect of the initial self-weight consolidation.

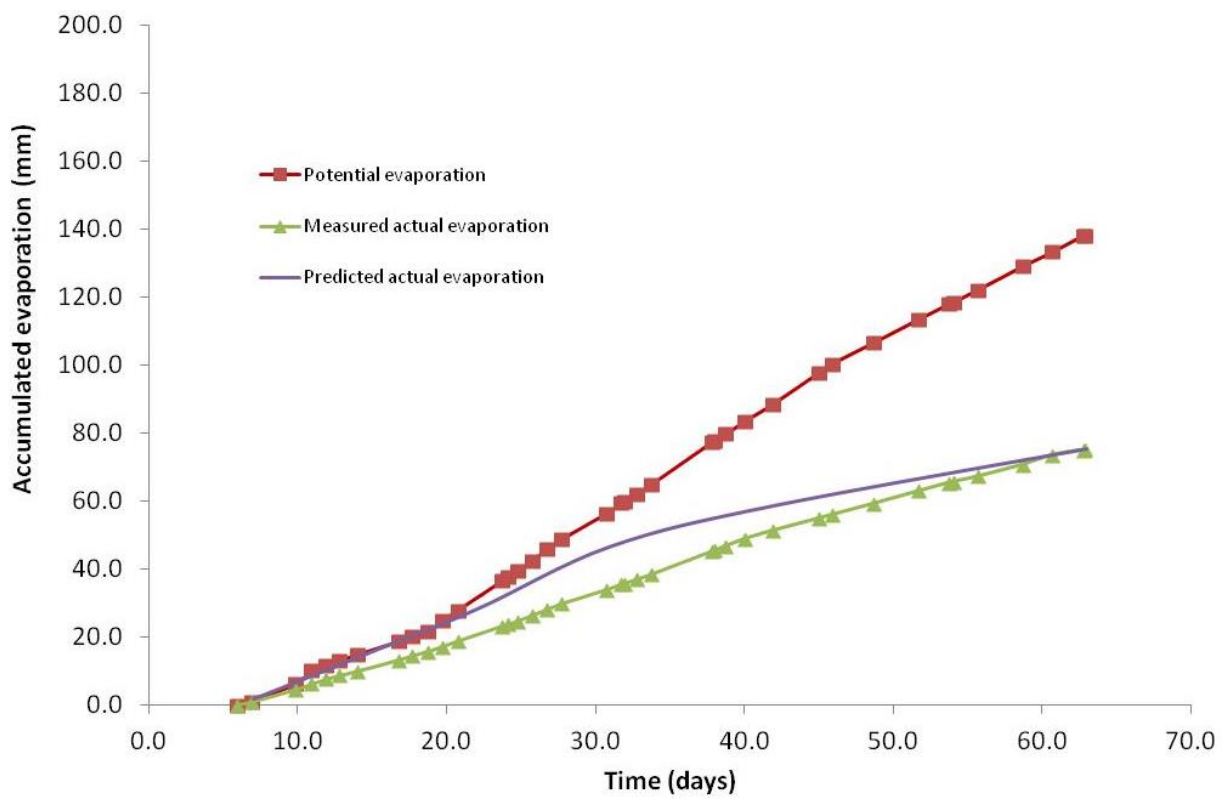

Figure 14 Comparison of the measured and predicted evaporation rates for the oil sands tailings 


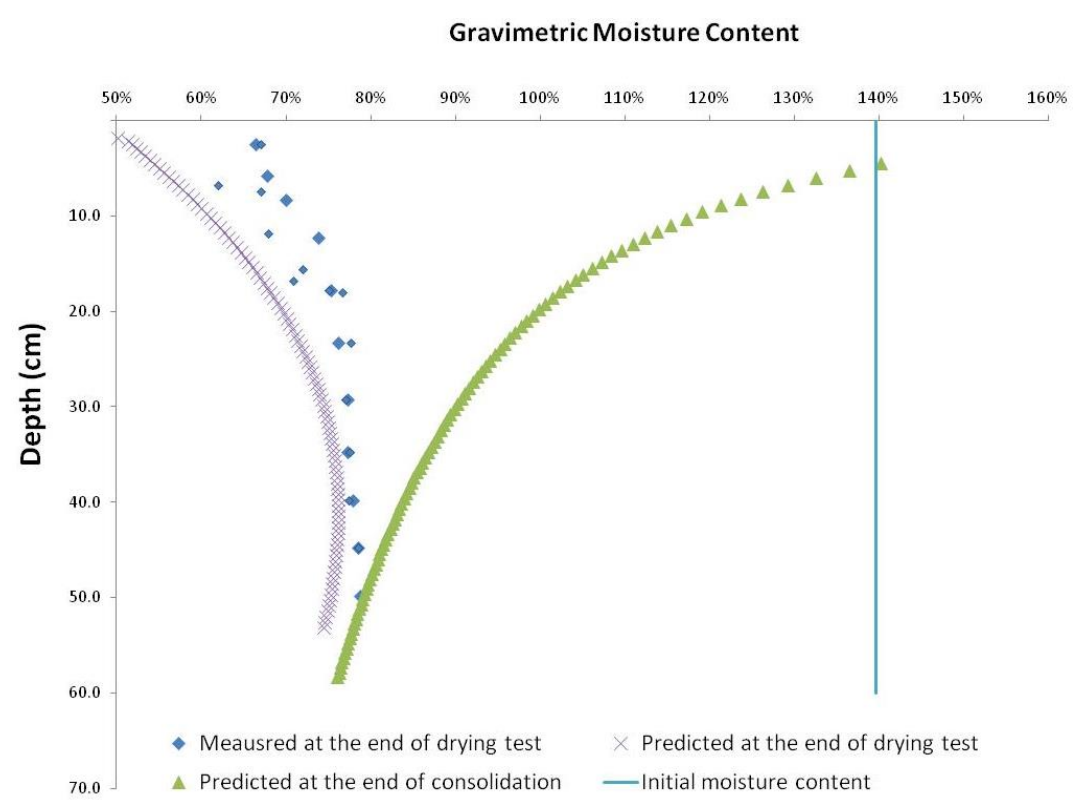

Figure 15 Comparison of the measured and predicted moisture content for the oil sands tailings

\section{$6 \quad$ Summary and conclusions}

The void ratio achieved during the early stage of tailings deposition is one of the key parameters that dictates the in situ tailings properties and the stability of the tailings deposits under long-term conditions. A geotechnical modelling approach is proposed to estimate the void ratio of tailings during thin layer deposition of tailings based on the design method developed by Li et al. (2009).

Since dewatering due to initial self-weight consolidation usually takes days for the tailings investigated, while further dewatering from evaporative drying can take months, a two-stage modelling approach is justified for many tailings management facilities. The model consists of the initial self-weight consolidation stage of freshly deposited tailings and a subsequent drying stage. Multiple deposition cycles can be modelled. Evaporative drying starts only when self-weight consolidation slows to the extent that less water than the potential evaporation is released. The self-weight consolidation model is based on the large strain consolidation theory (Gibson et al., 1967) modified to accommodate a power function for the compressibility. For drying, a new drying model is proposed following the framework proposed by Gilliland and Sherwood (1933) for moisture migration within fine-grained soils due to evaporative drying. The drying model also incorporates the soil water characteristic curve equation proposed by Fredlund and Xing (1994). Approximate analytical solutions were obtained for the governing equations.

Design tools (SWCONS and EVDRY) were developed using a Fortran code to integrate the analytical equations for self-weight consolidation and drying. The consolidation model was validated using $0.2-1.0 \mathrm{~m}$ high consolidation column tests and the drying model was validated using $0.2-0.8 \mathrm{~m}$ high drying column tests. The results indicate that the modelling approach can reasonably predict the volume change and actual evaporation during the transient stages of consolidation and drying. The drying model is able to simulate the drying process of consolidated tailings with a non-uniform void ratio profile and to predict formation of a crust under evaporative drying. The model also provides a way to evaluate water loss due to drying for water balance analyses. It should be noted that the models have been developed for tailings with low-salinity pore fluid and fluids that do not leave a thin film on the tailings surface during the evaporation process.

The design tools described in this paper provide a means to estimate the optimum layer thickness and a drying period for a specific project under specific weather conditions, in order to optimise the in situ density and stability of tailings deposits. 


\section{Acknow l edgements}

The authors would like to acknowledge P. Jarre and B. Shaw for approving the funding of this tailings research program by Golder Associates. The authors express thanks to Del Fredlund and Ken Bocking of Golder Associates and David Williams of University of Queensland for the discussions, and to F. Junqueira, E. Salfate and J. Stone of Golder Associates for carrying out the laboratory testing.

\section{References}

Ayad, R., Konrad, J.M. and Soulié, M. (1997) Desiccation of a sensitive clay: application of the model CRACK, in Canadian Geotechnical Journal, Vol. 34, pp. 943-951.

Abu-Hejleb, A.N. and Znidarcic, D. (1995) Desiccation theory for soft cohesive soils, Journal of Geotechnical Engineering, Vol. 121, No. 6, pp. 106-114.

Casteleirio, M., Krizek, R.J. and Edil, T.B. (1981) Mathematical model for one-dimensional desiccation and consolidation of sedimented soils, in International Journal for Numerical and Analytical Methods in Geomechanics, Vol. 5, pp. $195-215$.

Been, K. and Sills, G.C. (1981) Self-weight consolidation of soft soils: an experimental and theoretical study, Geotechnique, Vol. 31, No. 4, pp. 519-535.

Benson, R.E., Jr., and Sill, B.L. (1991) Evaporative drying of dredged material, in Journal of Waterway, Port, Coastal, Ocean Engineering, Vol. 117, No. 3, pp. 216-234.

Craig, R.F. (1987) Soil mechanics, London, New York, E \& FN Spon, 1997, 6th Edition.

Cooling, D.J. (2007) Improving the Sustainability of Residue Management Practices - Alcoa World Alumina Australia, Keynote Address, in Proceedings Tenth International Seminar on Paste and Thickened Tailings (Paste07), A.B. Fourie and R.J. Jewell (eds), 13-15 March 2007, Perth, Australia, Australian Centre for Geomechanics, Perth, pp. 3-16.

Consoli, N.C. and Sills, G.C. (2000) Soil formation from tailings: comparison of predictions and field measurements, in Geotechnique, Vol. 50, No. 1, pp. 25-33.

ERCB (2009) Energy Resources Conservation Board. Directive 074 - Tailings Performance Criteria and Requirements for Oil Sands Mining Schemes.

Fine Tailings Fundamentals Consortium (1995) Advances in oil sands tailings research, Alberta Department of Energy, Edmonton, Alberta, Canada.

Fredlund, D.G. (2006) Unsaturated soil mechanics in engineering practice, Terzaghi Lecture, in ASCE Journal of Geotechnical and Geoenvironmental Engineering, Vol. 132, No. 3 pp. 286-321.

Fredlund, D.G. and Rahardjo, H. (1993) Soil mechanics for unsaturated soils, New York, John Wiley \& Sons.

Fredlund, D.G. and Xing, A. (1994) Equations for the soil water characteristic curve, in Canadian Geotechnical Journal, Vol. 31, No. 3, pp. 521-532.

Fredlund, M.D., Wilson, G.W. and Fredlund, D.G. (2002) Representation and estimation of the shrinkage curve, in Proceedings of the 3rd International Conference on Unsaturated Soils, UNSAT 2002, Recife, Brazil, pp. 145-149.

Fredlund, M.D., Stone, J., Stianson, J. and Sedgwick, A. (2011) Determination of water storage and permeability functions for oil sands tailings, in Proceedings 15 International Conference on Tailings and Mine Waste 2011, Vancouver, BC, 6-9 November, pp. 315-328.

Gibson, R.E., England, G.L. and Hussey, M.J.L. (1967) The theory of one-dimensional consolidation of saturated clays, I. Finite nonlinear consolidation of thin homogeneous layers, in Geotechnique, Vol. 17, No. 2, pp. 261-273.

Gilliland, E.R. and Sherwood, T.K. (1933) The drying of solids, VI, Industrial and engineering chemistry, pp. 1134-1136.

Howell, T.A., Phene, C.J. and Meek, D.W. (1983) Evaporation from screened class A pans in a semi-arid climate, in Agriculture Meterology, Vol. 19, pp. 111-124.

Jewell, R.J. and Fourie, A.B. (eds) (2006) Paste and Thickened Tailings - A Guide, 2nd edition, Australian Centre for Geomechanics, Perth, $242 \mathrm{p}$.

Krizek, R., Casteleiro, M. and Edil, T. (1977) Desiccation and consolidation of dredged materials, in Journal of the Geotechnical Engineering Division, Vol. 103 (GT12), pp. 1399-1418.

Lee, K. and Sills, G.C. (1981) The consolidation of a soil stratum, including self-weight effects and large strains, in International Journal for Numerical and Analytical Methods in Geomechanics, Vol. 5, pp. 405-428.

Li, A.L. (2011) Prediction of tailings beach slopes and tailings flow profiles, in Proceedings 14th International Seminar on Paste and Thickened Tailings (Paste2011), R.J. Jewell and A.B. Fourie (eds), 5-7 April 2011, Perth, Australia, Australian Centre for Geomechanics, Perth, pp. 307-322.

Li, A.L., Been, K., Ritchie, D. and Welch, D. (2009) Stability of large thickened, non-segregated tailings slopes, in Proceedings 12 th International Seminar on Paste and Thickened Tailings (Paste09), R.J. Jewell, A.B. Fourie, S. Barrera, J. Wiertz (eds), 21-24 April 2009, Viña Del Mar, Chile, Gecamin Limited, Santiago, Australian Centre for Geomechanics, Perth, pp. 301-311.

Morris, P.H., Graham, J. and Williams, D.J. (1992) Cracking in drying soils, in Canadian Geotechnical Journal, Vol. 29, pp. $263-277$.

Morris, P.H., Wong, L.T. and Day, R.A. (2007) Journal of Waterway, Port, Coastal, Ocean Engineering, Vol. 133, No. 4, pp. $268-274$.

Richards, B.G. (1965) Determination of the Unsaturated Permeability and Diffusivity Functions from pressure plant outflow data with non-negligible membrane impedance, in Moisture Equilibria and Moisture Changes in Soils Beneath Covered Areas, G.D. Aitchison (ed), a Symposium Convened by Soil Mechanics Section, Commonwealth Scientific and Industrial Research Organisation (CSIRO), Australia. 
Stark, T.D., Choi, H. and Schroeder, P. (2005) Settlement of dredged and contaminated material placement area, I: Theory and use of primary consolidation, secondary compression, and desiccation of dredged fill, in Journal of Waterway, Port, Costal, and Ocean Engineering, Vol. 131, No. 2, pp. 43-51.

Swarbrick, G. and Fell, R. (1992) Modelling desiccating behaviour of mine tailings, in Journal of Geotechnical Engineering, Vol. 118, No. 2, pp. 540-555.

Wilson, G.W., Fredlund, D.G. and Barbour, S.L. (1994) Coupled soil-atmosphere modelling for soil evaporation, in Canadian Geotechnical Journal, Vol. 31, pp. 151-161.

Yao, D.T.C., de Oliveria-Filho, W.L., Cai, X.C. and Znidarcic, D. (2001) Numerical solution for consolidation and desiccation of soft soils, in International Journal for Numerical and Analytical Methods in Geomechanics, Vol. 26, pp. 139-161. 